\title{
Continues Mannitol Infusion Might Provide Effectiveness in Patient with Malignant MCA
}

\author{
Genc Struga* and Majlinda Shyti \\ Department of Neuroscience, Albania
}

*Corresponding author: Genc Struga, Department of Neuroscience, University Hospital Mother Tereza, Str. Kongresi i Manastirit,133, 1003 TIRANE Tirana, Albania.

Received Date: January 25, 2019

Published Date: March 01, 2019

\begin{abstract}
There are little data regarding the efficacy of decompressive craniotomy outside $48 \mathrm{~h}$ or in older patients. In the older patients with no clear indication for decompressive craniotomy proper administration antioedematous medical treatment in Neurovascular Intensive Unit might result lifesaving. Using continues infusion of Mannitol and continuously monitoring of volume and heart function, electrolyte balance with rapid management of hypernatraemia and hypokalaemia. renal follow up diuresis and clearance. glucose, and a follow up of osmolarity not to exceed 320 mOsm litre.
\end{abstract}

Abbreviations: Acute stroke; Malignant sylvian stroke; Decompressive craniectomy; Mannitol

\section{Introduction}

Decompressive craniectomy has reduced morbidity and mortality especially in people aged below 60 years and those operated within $48 \mathrm{~h}$ of malignant MCA stroke has class I indication. In the older patients with no clear indication for decompressive craniotomy proper administration anti-edematous medical treatment in Neurovascular Intensive Unit might result lifesaving Manntol an isomer of sorbitol has a low molecule weight osmotically active diuretic which besides antiedematous properties also has effect as free radical scavenger during ischemia Mannitol side effects are initial volume expansion with risk of pulmonary edema in patients with heart failure, hypovolaemia, metabolic acidosis, and electrolyte imbalance especially hypernatraemia and hypokalaemia. With subsequence of renal failure from hipovoloemia but also tubular necrosis. The increase osmolarity $>320$ mOsm liter in patients with hyperglycemia may result in neurological complications and heart failure.

\section{Case Report}

R.C 74 years old came to the emergency department with abrupt onset of inability to communicate and move her left limbs. In the neurological examination she was alert, able to perform simple commands. She presented with dysarthria and hemiparesis in her left limbs with predominance in the upper ones (1/5 vs. 2/5) Ct scan performed in the emergency department revealed a hypodense lesion in the frontal parietal lobe with tendency for haemorrhagic transformation. After that the patient was transferred to the neurovascular department. In the second day of hospitalisation she was with the eyes closed but reactive against verbal stimulus, left hemiplegic, with high values of arterial pressure $(160 / 90 \mathrm{mmHg}$ ) In the 3 day of hospitalisation her situation was deteriorated. She just reacted against pain stimulus localising it with her right arm. Her pupils were anisocoric, right more than left. The patient was feed with nasogastric tube. Her vital signs were in normal range. This situation lasted for 10 days. In the 11 day of hospitalisation she was able to react against verbal stimulus.

In the 16 day she was alert, able to respond to simple commands. Now her respiration is better, and she was without supplement of oxygen. In the 19 day she was able to move her limbs and to communicate. In the 21 day she was discharged from the hospital. Examination: Echocardiogram: Hypertrophied of interventricular septum. ECG: Sensual rhythm Blood analysis: glue (120-260 mg /dL): ALT, AST normal, creatinine, uraemia normal, K (3.2-3.8): Na (133-145)WBC in hospitalisation day were $11.2 * 10^{\wedge} 3$ and increased till $* 15.6^{*} 10^{\wedge} 3$ in 03.07 .2018 .HbA1c 5.2Treatment: Sol Manitol 20\% 125 cc four times, isotonic saline + electrolytes, sol ceftriaxone, antihypertensives such as (losaran, 
bisoprolol, amlodipine) and Ranital i/v profilaxy, insulin therapy. In the fifth day of hospitalisation Sol Manitol was administered with continuous perfusion with a rate of $33 \mathrm{ml} / \mathrm{h}$ and also was added prednisolone 1 ampule in the morning (Figure1).

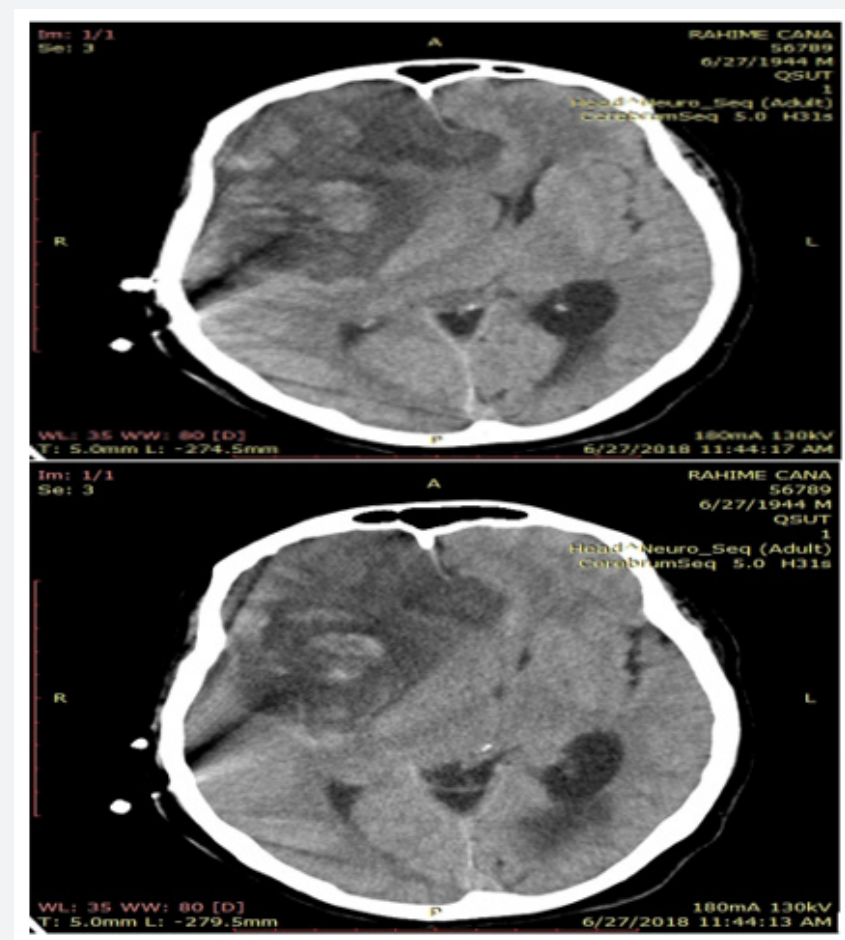

Figure 1: CT 6. 27. 2018 hypodense lesion with haemorrhagic transformation, fronto temporal dex, MCA+ ACA territory with median structure shift to the left $17 \mathrm{~mm}$ and compression of basal cistern of the right side.

Sol Manitol 20\% infusion was administered in this manner for 4 days, than in a separated manner 4 times per day with a tendency for progressive lowering until it was stopped in 10.07(17 day after hospitalisation). Enoxaparine was started in the 11 day of hospitalisation.

She was discharged from hospital in 15.07.2018 (21 day after), able to communicate and to move her right limbs but with the persistency of the left hemiplegia. She was continuously was under rehabilitation, his feeding was improved, and nasogastric tube was withdrawn, urinary vesicle rehabilitation and several attempts were made to with-drawn the catheter unsuccessfully. The motor weakness continues to remain with low spasticity level.

\section{Discussion}

Taking in consideration Mannitol effects as volume expansion with risk of pulmonary edema in patients with heart failure important is cardiac screening and follow up, additional diuretic can potentiate the effect of Manntol and reduced the risk of heart failure. Maintaining volaemia, electrolyte balance with rapid management of hypernatraemia and hypokalaemia. renal follow up diuresis and clearance. An appropriate management of blood glucose is also mandatory. A follow up of osmolarity not to exceed 320 mOsm litre makes possible to prevent neurological complications and the heart failure also to maintain appropriate renal function (Figure 2).

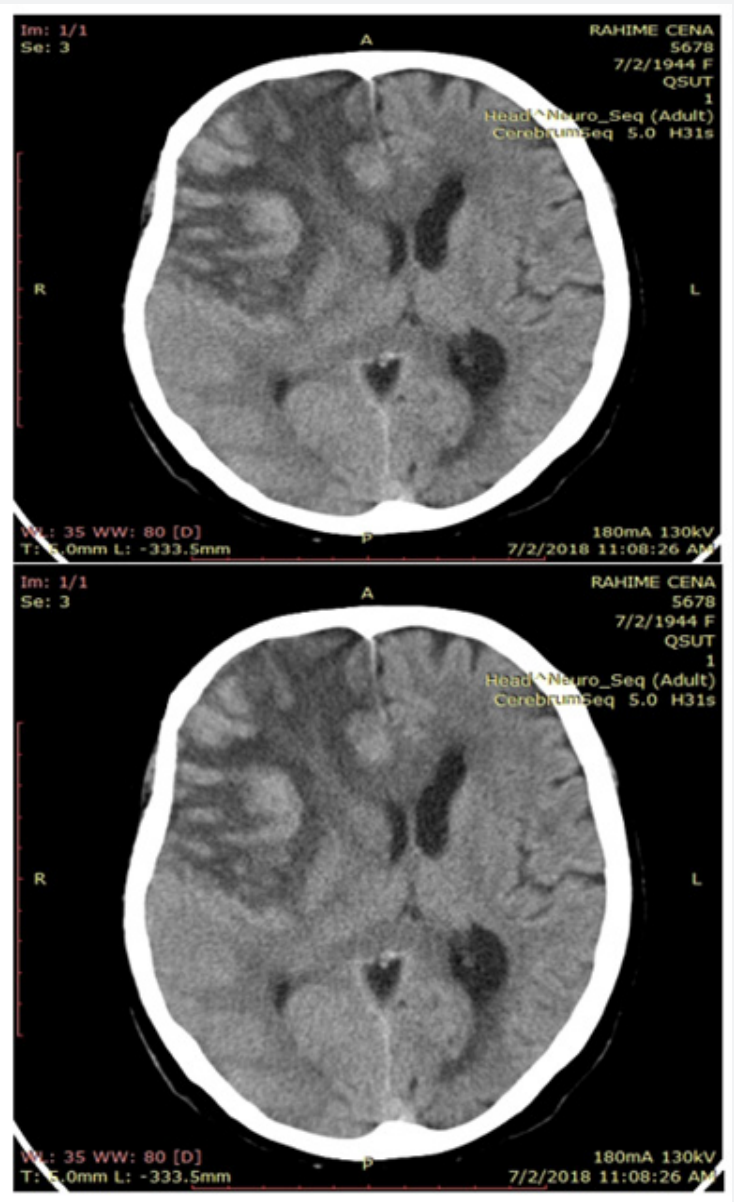

Figure 2: CT 7/2/2018 hypodens lesion with haemorrhagic transformation, frontal- temporal dexter , MCA+ ACA territory with median structure shift to the left $8 \mathrm{~mm}$.

\section{Conclusion}

Substantial contributions to conception and design of the study and performed data analysis and interpretation. Performed data acquisition, as well as provided administrative, technical, and material support: Majlinda Shyti. In the older patients with no clear indication for decompressive craniotomy proper administration antiedematous medical treatment in Neurovascular Intensive Unit might result lifesaving. Using continues infusion of Mannitol and continuously monitoring of volume and heart function, electrolyte balance with rapid management of hypernatraemia and hypokalaemia. renal follow up diuresis and clearance. glucose, and a follow up of osmolarity not to exceed 320 mOsm litre.

\section{Acknowledgement}

None.

\section{Conflict of Interest}

No conflict of interest.

\section{References}

1. Bansal H, Chaudhary A, Singh A, Paul B, Garg R (2015) Decompressive craniectomy in malignant middle cerebral artery infarct: An institutional experience. Asian J Neuro surg 10(3): 203-206. 